\title{
Analytical Procedure Linearity
}

National Cancer Institute

\section{Source}

National Cancer Institute. Analytical Procedure Linearity. NCI Thesaurus. Code C134033.

The ability (within a given range) to obtain test results which are directly proportional to the concentration (amount) of analyte in a sample. 